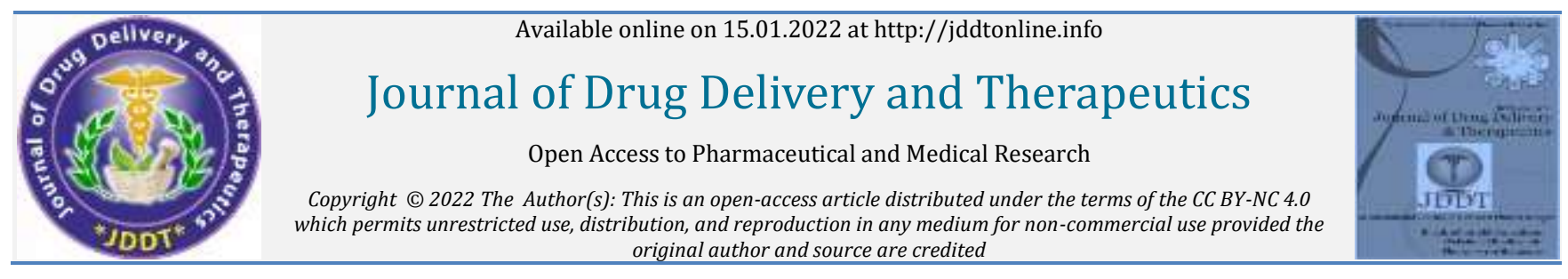

Open 1 Access Full Text Article original author and source are credited

\title{
Preparation, evaluation and optimization of solid lipid nanoparticles composed of pantoprazole
}

\author{
Atiya Sheikh*, Sandesh Asati \\ Radharaman College of Pharmacy, Ratibad, Bhopal, MP, 462044, India
}

Article Info:

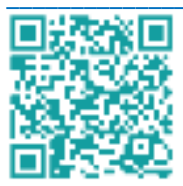

Article History:

Received 09 November 2021

Reviewed 18 December 2021

Accepted 22 December 2021

Published 15 January 2022

Cite this article as:

Sheikh A, Asati S, Preparation, evaluation and optimization of solid lipid nanoparticles composed of pantoprazole, Journal of Drug Delivery and Therapeutics. 2022; 12(1):1218

DOI: http://dx.doi.org/10.22270/jddt.v12i1.5154

*Address for Correspondence:

Atiya Sheikh, Radharaman College of Pharmacy, Ratibad, Bhopal, MP, 462044, India

\author{
Abstract
}

Nanoparticles are a promising medication delivery method that can deliver drugs in a controlled and targeted manner. They're made to release the medicine in close proximity to the target tissue. Solid lipid nanoparticles (SLNs) are a new type of submicron-sized lipid emulsion in which solid lipid replaces liquid lipid (oil). The goal of this study was to create solid lipid nanoparticles (SLN) containing pantoprazole (a proton pump inhibitor) and improve the drug's entrapment efficiency in SLN. This was accomplished by integrating the medication into solvent-injection-prepared solid lipid nanoparticles (SLN). During formulation development, the component concentrations were optimized, and then the particles were characterized in terms of particle size, zeta potential, drug loading, percent drug entrapment, stability studies, and drug release behavior. There was no interaction between the medication and the excipients in FT-IR experiments. The improved formulation's percent $\mathrm{EE}$, particle size, and drug content were found to be $91.88 \pm 1.38,7.16 \pm 0.26 \mu \mathrm{m}$ and $97.20 \pm 1.46$ respectively. F6 was shown to be the most promising formulation among all created formulations in this investigation. For 30 days, stability tests were conducted (F6) at refrigerated temperature $\left(4.0 \pm 0.2^{\circ} \mathrm{C}\right)$, room temperature $\left(25-28 \pm 2^{\circ} \mathrm{C}\right)$, and $45 \pm 1^{\circ} \mathrm{C}$. The current project also aims to improve the formulation's pharmacological acceptability.

Keywords: Solid lipid nanoparticles, Pantoprazole, Solvent-injection method, Entrapment efficiency

\section{INTRODUCTION}

Solid lipid nanoparticles (SLNs) were first used in drug delivery around two decades ago, and a lot of research has been done in this sector since then ${ }^{1-5}$. SLNs for oral medication administration are designed to prevent the drug from being metabolized in its initial transit by the lymphatic system. Transcellular transport through the enterocyte and phagocytosis of the medications by Mast cells of payer's patches lining the intestinal mucosa ${ }^{6-8}$ are the two mechanisms by which pharmaceuticals are taken into the lymphatic system. The solidification of lipid nano emulsions is used in the manufacture of this nano particulate system ${ }^{9}$. High shear homogenization, ultrasonic, high pressure homogenization, solvent emulsification/evaporation, and the microemulsion process are some of the different technologies available for the manufacturing of SLNs ${ }^{10}$. Fatty acids, mono, di, and triglycerides, phospholipids, and other excipients employed in the formulation of SLNs are part of the physiological constitution and so biocompatible with the body 11-13. Polymeric nanoparticles, fat emulsions, and liposomes have all been found to have disadvantages over $\mathrm{SLNs}^{14}$. In comparison to polymers, SLNs can be generated on a massive scale and are also biocompatible with the body ${ }^{15}, 16$. Because the medication is immobilised within the lipid, SLNs have a longer release time than emulsion formulations ${ }^{17}$, and they also have superior physical and chemical durability than liposomes ${ }^{18}$. Proteins, protein medicines, vaccines, and lipophilic water insoluble pharmaceuticals have all been carried by this delivery system ${ }^{19}$. SLNs are a promising delivery strategy for lipophilic medicines whose absorption is limited by the drug's water solubility20-22. Furthermore, because of their affinity for lipids, such medicines are easier to incorporate into SLN. Entrapping a hydrophilic drug inside the hydrophobic matrix of SLNs, on the other hand, is a major difficulty because the drug has a strong inclination to partition in water during the production process. Although a few hydrophilic molecules such as thymocratin, insulin, diminazene, and thymopentin ${ }^{23-26}$ have been integrated into SLNs, there is still a lot of room for hydrophilic pharmaceuticals to be entrapped in lipid nanoparticles. Pantoprazole is a commonly used proton pump inhibitor that is effective in the treatment of acid-related disorders ${ }^{27}$. It is also effective against Helicobacter biliary infections when given alone or in combination with other antibiotics such metronidazole, clarithromycin, or amoxicillin ${ }^{28,}$ 29. 5(difluoromethoxy)-2-[(3, 4-dimethoxy-2-pyridinyl) methyl] sulfinyl]-benzimidazole sodium sesquihydrate ${ }^{30}$ was the first water soluble benzimidazole. By preferentially engaging with the stomach proton pump (K/H-ATPase) in the parietal cell secretory membrane, a molecule containing benzimidazole substitution inhibits gastric acid secretion effectively and for a long time ${ }^{31}$. When compared to its analogues (e.g., omeprazole), pantoprazole offers various advantages, including a particular binding site, higher stability in a 
neutral pH environment, and a longer duration of action ${ }^{32}$. Furthermore, it has no ability to stimulate or inhibit CYP 45033. It inhibits acid production more selectively than other proton pump inhibitors ${ }^{34}$. The goal of this study is to create, characterize, and test pantoprazole-loaded solid lipid nanoparticles in vitro.

\section{MATERIALS AND METHODS}

\section{Materials}

Pantoprazole was supplied from Arch Pharmalabs Ltd. Mumbai, India. Ethyl cellulose, HPMC K100 M, Poly vinyl alcohol, dichloromethane, and ethanol were supplied from central drug house, Delhi. The solvents (acetone, methanol) of analytical grade were purchased from SD fine chemicals, Mumbai. All other ingredients used were of analytical grade. Triple distilled water was generated in house.

\section{Methods}

\section{FTIR Spectroscopy}

FTIR spectroscopy was used to identify pantoprazole in relation to a marker component. Pantoprazole was obtained as white to off white crystalline powder. It was identified from the result of IR spectrum as per specification.

\section{Determination of $\lambda_{\max }$ of pantoprazole}

Pantoprazole, $100 \mathrm{mg}$, was accurately weighted into a $100 \mathrm{ml}$ volumetric flask, dissolved in $0.1 \mathrm{M} \mathrm{HCl}$, and the volume was made up with $0.1 \mathrm{M} \mathrm{HCl}$. Pipette $1 \mathrm{ml}$ of this solution into a 10 ml volumetric flask with $0.1 \mathrm{M} \mathrm{HCl}$ as the volume and marks it as Stock. Prepare an appropriate dilution to bring the concentration down to $2-10 \mu \mathrm{g} / \mathrm{ml}$. The resulting solution is scanned with a UV spectrophotometer (UV-1700 Shimadzu corporation, Japan) in the range of (200-400 nm) to determine the absorption maximum ( $\lambda$ max). Concentration vs. absorbance was shown on a graph.

\section{Preparation of solid lipid nanoparticles}

Solvent injection technique ${ }^{35,36}$ was used to make solid lipid nanoparticles with ethanol as the organic solvent. Ethyl cellulose, chitosan, medicine, HPMC K100, and PVA are dissolved in ethanol and warmed to $70^{\circ} \mathrm{C}$ in a definite ratio. To prepare the aqueous phase, a specific amount of DCM is added to the phosphate buffer solution ( $\mathrm{pH} 7.4)$ and held for stirring at $70^{\circ} \mathrm{C}$. With the use of a hypodermic needle, the organic phase was introduced drop by drop to the prewarmed aqueous solution while stirring. To obtain nanoparticles, the mixture was sonicated (Ultra sonicator, Bath type, Electronic India) for varied times. The best parameters for the manufacture of SLN using a comparable procedure were concentrations in a fixed ratio and maximum sonication time, which resulted in maximum entrapment efficiency and regulated release. To assess the influence of surfactant and sonication time on the effectiveness of the SLNs, twelve formulations were created using varying concentrations of PVA and sonication duration Table 1.

Table 1 Composition of different formulation of SLNs

\begin{tabular}{|c|c|c|c|c|c|c|c|c|}
\hline \multirow[b]{2}{*}{ F. Code } & \multicolumn{8}{|c|}{ INGREDIENTS } \\
\hline & $\begin{array}{c}\text { Pantopraz } \\
\text { ole (mg) }\end{array}$ & $\begin{array}{c}\text { Ethyl } \\
\text { cellulose } \\
\text { (mg) }\end{array}$ & $\begin{array}{l}\text { Chitosa } \\
\text { n (mg) }\end{array}$ & $\begin{array}{c}\text { HPMC } \\
\text { K100 (mg) }\end{array}$ & $\begin{array}{l}\text { Polyvinyl } \\
\text { alcohol } \\
(\% w / v)\end{array}$ & DCM (ml) & water $(\mathrm{ml})$ & Total \\
\hline F1 & 30 & 20 & & & 40 & 5 & 5 & 100 \\
\hline F2 & 30 & 30 & & & 30 & 5 & 5 & 100 \\
\hline F3 & 30 & 40 & & & 20 & 5 & 5 & 100 \\
\hline $\mathrm{F} 4$ & 30 & 50 & & & 10 & 5 & 5 & 100 \\
\hline F5 & 30 & & 20 & & 40 & 5 & 5 & 100 \\
\hline F6 & 30 & & 30 & & 30 & 5 & 5 & 100 \\
\hline F7 & 30 & & 40 & & 20 & 5 & 5 & 100 \\
\hline F8 & 30 & & 50 & & 10 & 5 & 5 & 100 \\
\hline F9 & 30 & & & 20 & 40 & 5 & 5 & 100 \\
\hline F10 & 30 & & & 30 & 30 & 5 & 5 & 100 \\
\hline F11 & 30 & & & 40 & 20 & 5 & 5 & 100 \\
\hline F12 & 30 & & & 50 & 10 & 5 & 5 & 100 \\
\hline
\end{tabular}

\section{Characterization of SLN}

\section{Surface charge and vesicle size}

The size and size distribution of the vesicles, as well as their surface charge, were assessed using the Dynamic Light Scattering method (DLS) (Malvern Zetamaster, ZEM 5002, Malvern, UK).
From their electrophoretic mobility, the zeta potential was determined according to Helmholtz-Smoluchowsky. A zetasizer was employed on a large bore measuring cell to measure zeta potential with field strength of $20 \mathrm{~V} / \mathrm{cm}$. The conductivity of the samples was corrected to $50 \mathrm{IS} / \mathrm{cm}^{37,38}$ by diluting them with 0.9 percent $\mathrm{NaCl}$.

Entrapment efficiency 
The mass of formulations associated drug to the overall mass of drug was used to calculate the drug's entrapment efficiency. The dialysis method was used to measure entrapment efficiency. Dialysis was used to separate pantoprazole-entrapped solid lipid nanoparticles from the free drug. The free pantoprazole was dialyzed for 24 hours in $50 \mathrm{ml}$ of phosphate buffer $\mathrm{pH} 7.4$ saline after the above formulations were put into dialysis bags. The dialysate's absorbance was measured at $274 \mathrm{~nm}$ against blank phosphate buffer pH 7.4 saline and the absorbance of the corresponding blank phosphate buffer $\mathrm{pH} 7.4$ saline was also measured. The absorbance difference based on the standard curve might be used to calculate the concentration of free pantoprazole. The absorbance at $274 \mathrm{~nm}$ for known doses of pantoprazole solution was used to create a standard curve ${ }^{39}$.

\section{Drug content}

$1 \mathrm{ml}$ of suspension from the prepared SLNs formulation is dissolved in $10 \mathrm{ml}$ of 7.4 PBS buffer and ethanol combination. A UV spectrophotometer set to $274 \mathrm{~nm}$ was used to determine the quantity of pantoprazole. The placebo formulation, which was made in the same way as the drugloaded SLNs, was utilized as a control. The overall amount of medication was determined.

\section{In vitro drug release}

The release of pantoprazole was calculated with the help of standard curve of pantoprazole.

In vitro drug release was tested on the prepared SLNs delivery system. The USP XXII paddle type dissolving test apparatus was used for the drug release experiments. The dissolution experiment was conducted in a $900 \mathrm{ml}$ dissolution media (PBS pH 7.4) that was agitated at $100 \mathrm{rpm}$ and kept at $370.2^{\circ} \mathrm{C}$. At varied time intervals, samples were extracted and compensated with the equal amount of fresh dissolving medium. PBS was used to dilute the sample to a maximum of $10 \mathrm{ml}(\mathrm{pH} 7.4)$. The withdrew samples were spectrophotometrically tested for pantoprazole at $274 \mathrm{~nm}$ with a UV visible spectrophotometer. The release of pantoprazole was calculated using the pantoprazole standard curve.

\section{Mathematical treatment of in-vitro release data}

When mathematical formulas that express dissolve results as a function of some of the dosage form properties are applied, quantitative analysis of the values obtained in dissolution/release tests becomes easier.

\section{Zero-order kinetics}

The pharmaceutical dosage forms following this profile release the same amount of drug by unit of time and it is the ideal method of drug release in order to achieve a pharmacological prolonged action. The following relation can, in a simple way, express this model:

Following this profile, pharmaceutical dosage forms release the same quantity of medication per unit of time, making it the optimal technique of drug release for achieving pharmacologically extended activity. This model can be expressed in a simple fashion using the following relation:

$$
\mathbf{Q}_{\mathbf{t}}=\mathbf{Q}_{\mathbf{o}}+\mathbf{K}_{\mathbf{o}} \mathbf{t}
$$

Where $Q_{t}$ is the amount of drug dissolved in time $t, Q_{o}$ is the initialamount of drug in the solution (most times, $Q_{0}=0$ ) and $\mathrm{K}_{\mathrm{o}}$ is the zero order release constant ${ }^{40}$.

\section{First-order kinetics}

This model is expressed by the following relationship:

$$
\log Q_{t}=\log Q_{0}+\frac{K_{1} t}{2.303}
$$

Where $Q_{t}$ is the amount of drug dissolved in time $t, Q_{o}$ is the initial amount of drug in the solution and $\mathrm{K}_{1}$ is the zero order release constant.

A graph showing the decimal logarithm of the drug's released amount vs time will be linear as a result. Pharmaceutical dosage forms that follow this dissolution profile, such as those containing water-soluble pharmaceuticals in porous matrices, release drug according to the amount of drug remaining in their interior, resulting in a decrease in the amount of drug released per unit of time.

\section{Korsmeyer-peppas model}

Korsmeyeret al. used a simple empirical equation to describe general solute release behaviour from controlled release polymer matrices:

$$
\frac{\mathrm{M}_{\mathbf{4}}}{\mathrm{M}_{\mathbf{w}}}=\mathbf{a} \mathbf{t}^{n}
$$

Where $M_{t} / M_{\infty}$ is fraction of drug released, a is kinetic constant, $\mathrm{t}$ is release time and $\mathrm{n}$ is the diffusional exponent for drug release. ' $n$ ' is the slope value of $\log M_{t} / M_{\infty}$ versus $\log$ time curve. Peppas stated that the above equation could adequately describe the release of solutes from slabs, spheres, cylinders and discs, regardless of the release mechanism. Peppas used this $n$ value in order to characterize different release mechanisms, concluding for values for a slab, of $n=0.5$ for fickian diffusion and higher values of $n$, between 0.5 and 1.0, or $n=1.0$, for mass transfer following a non-fickian model. In case of a cylinder $n=0.45$ instead of 0.5 , and 0.89 instead of 1.0. This equation can only be used in systems with a drug diffusion coefficient fairly concentration independent. To the determination of the exponent $n$ the portion of the release curve where $M_{t} / M_{\infty}<0.6$ should only be used. To use this equation it is also necessary that release occurs in a one-dimensional way and that the system widththickness or length-thickness relation be at least 10. A modified form of this equation was developed to accommodate the lag time $(I)$ in the beginning of the drug release from the pharmaceutical dosage form:

$$
\frac{\mathrm{M}_{\mathrm{r} l}}{\mathrm{M}_{\mathbf{w}}}=\mathbf{a}(\mathbf{t}-l)^{n}
$$

When there is the possibility of a burst effect, $b$, this equation becomes:

$$
\frac{M_{4}}{M_{\mathbf{m}}}=\mathbf{a t} \mathbf{t}^{n}+\mathbf{b}
$$

In the absence of lag time or burst effect, $l$ and $b$ value would be zero and only $a^{n}$ is used. This mathematical model, also known as Power Law, has been used very frequently to describe release from several different pharmaceutical modified release dosage forms ${ }^{41,42}$.

\section{Stability studies}

For three months, drug-loaded SLNs were studied at three different temperatures: refrigeration temperature $\left(4.0 \pm 0.2^{\circ} \mathrm{C}\right)$, room temperature $\left(25-28 \pm 2^{\circ} \mathrm{C}\right)$, and $45 \pm 1^{\circ} \mathrm{C}$. To avoid any interaction between the formulation and the 
container glass, the stability study formulation was stored in a borosilicate container. Physical changes and pharmacological content were examined in the formulations.

\section{RESULTS AND DISCUSSIONS}

Pantoprazole was discovered to be a white to off-white crystalline powder with no odour or flavour. Pantoprazole (pure medication) has a melting point of 151-153 degrees Celsius. FTIR spectroscopy was used to identify pantoprazole in relation to a marker component. The result of the IR spectrum was used to identify it, as shown in fig. 1 . Pantoprazole calibration curve at $274 \mathrm{~nm}$ was found to be linear in the concentration range of $2-10 \mu \mathrm{g} / \mathrm{ml}$ fig. 2 . Table 2 shows the particle size, drug content, and entrapment efficiency of pantoprazole SLNs formulation. The optimised SLNs formulation (F6) has a percent entrapment efficiency of $91.88 \pm 1.38$. It was discovered that as the polymer concentration and staring duration were increased, the percent drug entrapment decreased slightly. It is due to the medicine being leached out of solid particles when the mechanical force is increased by using a stirrer and the particle size is reduced. The drug concentration and particle size of the improved SLNs formulation (F6) were found to be $7.16 \pm 0.26 \mu \mathrm{m}$ and $97.20 \pm 1.46$, respectively. SEM imaging of
SLNs should provide information on their morphology and size. Figure 3 shows SEM images of pantoprazole derived from SLNs. The round shape of the pantoprazole SLNs is confirmed by SEM micrographs. The F6 formulation was chosen as the best option. After 12 hours of in vitro drug release, optimized prepared SLNs (F6) were found to be $98.07 \pm 0.74$ Table 3 . To identify the specific mechanism of drug release, the in vitro release data of F6 were fitted into multiple kinetic models, including zero-order, first-order, and Korsmeyer Peppas equations. When the regression coefficient values of were examined, the ' $r$ ' values of zero order were found to be the highest, 0.958 , showing that drug release from formulations followed zero order release kinetics Table 4. Stability tests were conducted with an optimized formulation that was stored at $4 \pm 1^{\circ} \mathrm{C}$, RT and $45 \pm 1^{\circ} \mathrm{C}$ for 30 days. Optical microscopy and a calibrated ocular micrometer were used to determine the particle size of the formulation. At RT, the particle size of the SLNs increased, which could be due to the aggregation of SLNs at higher temperatures. The SLNs aggregate at $45 \pm 2{ }^{\circ} \mathrm{C}$, indicating that these SLNs were unstable at higher temperatures. At higher temperatures, such as $45 \pm 2^{\circ} \mathrm{C}$, the percent efficiency of SLNs also decreases.

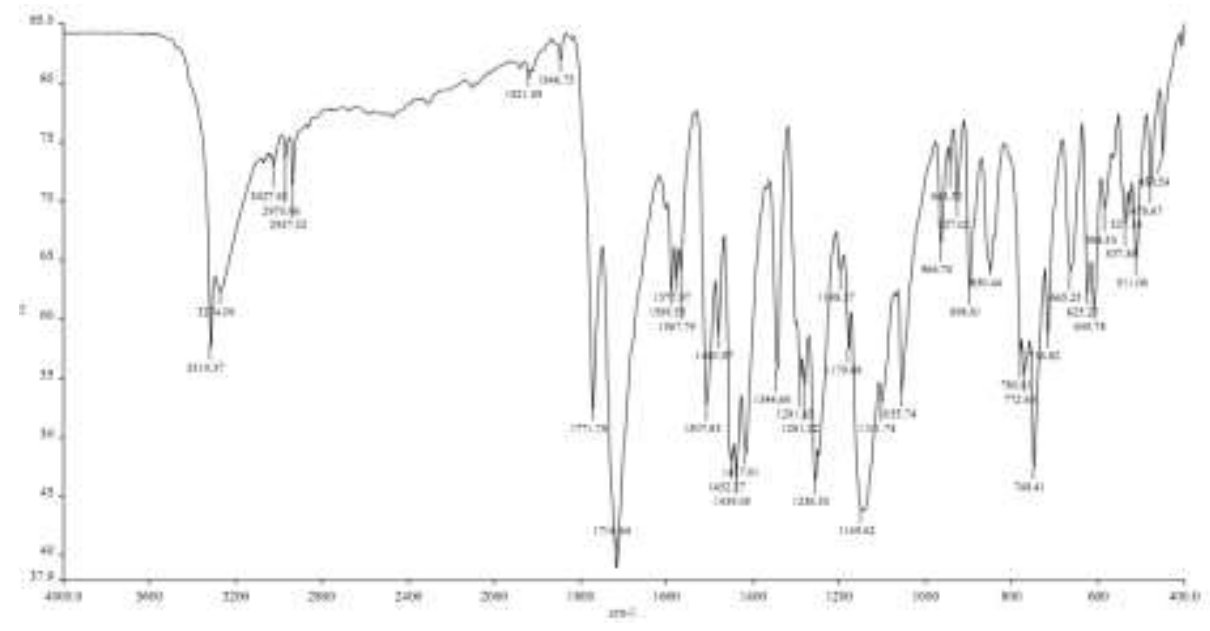

Figure 1: FT-IR spectrum of pure drug (Pantoprazole)

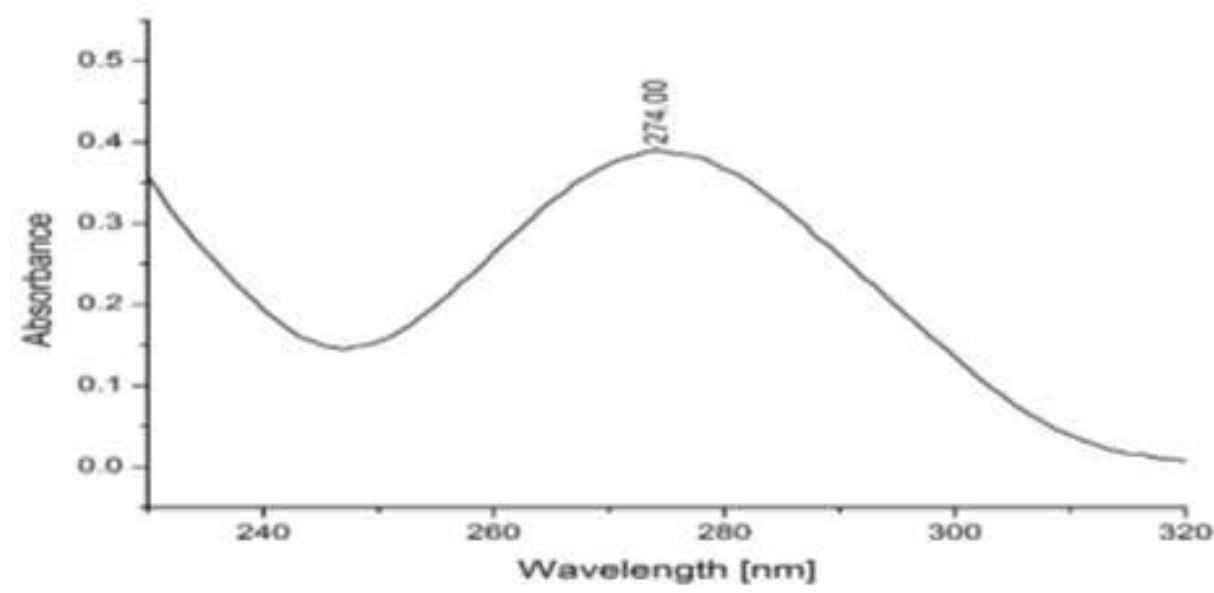

Figure 2: Wavelength maxima of pantoprazole in phosphate buffer pH 7.4 
Table 2: Result for particle size, drug content and entrapment efficiency of drug loaded SLNs

\begin{tabular}{|c|c|c|c|c|}
\hline S. No. & Formulation Code & Particle Size $(\mu \mathrm{m})$ & Drug Content (\%) & Entrapment Efficiency (\%) \\
\hline 1. & F1 & $6.24 \pm 0.11$ & $91.22 \pm 1.37$ & $68.56 \pm 1.03$ \\
\hline 2. & F2 & $7.86 \pm 0.20$ & $94.01 \pm 1.41$ & $75.96 \pm 1.14$ \\
\hline 3. & F3 & $6.65 \pm 0.16$ & $88.57 \pm 1.33$ & $64.53 \pm 0.97$ \\
\hline 4. & F4 & $7.10 \pm 0.23$ & $85.88 \pm 2.29$ & $67.84 \pm 1.02$ \\
\hline 5. & F5 & $6.50 \pm 0.18$ & $84.56 \pm 1.27$ & $68.66 \pm 2.03$ \\
\hline 6. & F6 & $7.16 \pm 0.26$ & $97.20 \pm 1.46$ & $91.88 \pm 1.38$ \\
\hline 7. & F7 & $6.30 \pm 0.21$ & $91.17 \pm 0.37$ & $74.93 \pm 1.12$ \\
\hline 8. & F8 & $7.12 \pm 0.10$ & $91.34 \pm 1.37$ & $55.36 \pm 0.83$ \\
\hline 9. & F9 & $6.45 \pm 0.15$ & $91.03 \pm 1.37$ & $68.85 \pm 3.03$ \\
\hline 10. & F10 & $7.44 \pm 0.22$ & $95.03 \pm 2.43$ & $75.57 \pm 1.13$ \\
\hline 11. & F11 & $6.34 \pm 0.14$ & $91.46 \pm 1.37$ & $61.33 \pm 1.92$ \\
\hline 12. & F12 & $7.71 \pm 0.26$ & $87.33 \pm 1.31$ & $59.15 \pm 0.89$ \\
\hline
\end{tabular}

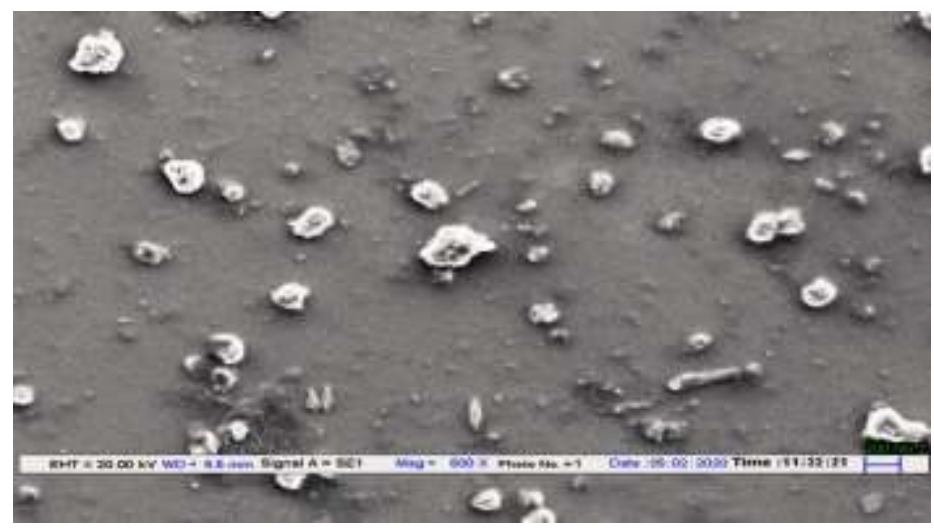

Figure 3: SEM Photograph of Pantoprazole Loaded SLNs

Table 3: Cumulative \% drug release of pantoprazole nanoparticles formulations

\begin{tabular}{|c|c|c|c|c|}
\hline \multirow{2}{*}{ S. No. } & \multirow{2}{*}{ Time in hours } & F2 & F6 & F10 \\
\cline { 3 - 5 } & 1 & $2.84 \pm 0.34$ & $2.77 \pm 0.26$ & $2.08 \pm 0.07$ \\
\hline 1. & 2 & $12.32 \pm 2.04$ & $17.05 \pm 0.72$ & $10.65 \pm 0.16$ \\
\hline 2. & 3 & $21.81 \pm 0.22$ & $20.91 \pm 0.69$ & $22.47 \pm 2.03$ \\
\hline 3. & 4 & $26.95 \pm 0.25$ & $29.57 \pm 0.34$ & $32.03 \pm 0.47$ \\
\hline 4. & 5 & $32.96 \pm 1.47$ & $35.95 \pm 0.92$ & $37.09 \pm 0.93$ \\
\hline 5. & 6 & $37.39 \pm 1.54$ & $42.96 \pm 1.15$ & $43.55 \pm 0.95$ \\
\hline 6. & 7 & $44.87 \pm 0.64$ & $49.73 \pm 0.82$ & $50.22 \pm 0.86$ \\
\hline 7. & 8 & $52.41 \pm 0.92$ & $57.59 \pm 1.17$ & $58.46 \pm 1.12$ \\
\hline 9. & 9 & $58.28 \pm 0.67$ & $67.51 \pm 1.04$ & $65.99 \pm 0.86$ \\
\hline 10. & 10 & $64.38 \pm 1.13$ & $77.28 \pm 0.48$ & $72.55 \pm 1.22$ \\
\hline 11. & 11 & $80.49 \pm 1.83$ & $88.37 \pm 1.82$ & $80.48 \pm 1.02$ \\
\hline 12. & 12 & $87.07 \pm 1.06$ & $98.07 \pm 0.74$ & $90.02 \pm 0.78$ \\
\hline
\end{tabular}


Table 4: Regression analysis data of SLN Formulation

\begin{tabular}{|c|c|c|c|}
\hline Formulation & Zero order & First order & Pappas plot \\
\hline F6 & $\mathrm{R}^{2}=0.958$ & $\mathrm{R}^{2}=0.875$ & $\mathrm{R}^{2}=0.979$ \\
\hline
\end{tabular}

\section{CONCLUSION}

This study shows that pantoprazole-loaded SLNs may be generated and described satisfactorily. As a result, the solvent injection technique appears to be a good way for preparing nano suspensions of pharmaceuticals such as pantoprazole in order to improve dissolution rate. As a result, SLN's drug delivery system delivers site-specific medication and extends the dosing interval, boosting patient compliance.

\section{REFERENCES}

1. Manjunath K, Venkateswarlu VJ. Pharmacokinetics, tissue distribution and bioavailability of clozapine solid lipid nanoparticles after intravenous and intraduodenal administration. J Control Release, 2005; 107:215-228. https://doi.org/10.1016/j.jconrel.2005.06.006

2. Puglia C, Blasi P, Rizza L, Schoubben A, Bonina F, Rossi C, Ricci M. Lipid nanoparticles for prolonged topical delivery: an in vitro and in vivo investigation. Int J Pharm. 2008; 357(1-2):295-304. https://doi.org/10.1016/j.ijpharm.2008.01.045

3. Mei Z, Li X, Wu Q, Hu S, Yang X. The research on the antiinflammatory activity and hepatotoxicity of triptolide-loaded solid lipid nanoparticle. Pharmacol Res. 2005 Apr; 51(4):34551. https://doi.org/10.1016/j.phrs.2004.10.007

4. Pandey R, Sharma S, Khuller GK. Oral solid lipid nanoparticlebased antitubercular chemotherapy. Tuberculosis (Edinb). 2005; 85(5-6):415-20. https://doi.org/10.1016/j.tube.2005.08.009

5. Tabatt K, Sameti M, Olbrich C, Müller RH, Lehr CM. Effect of cationic lipid and matrix lipid composition on solid lipid nanoparticle-mediated gene transfer. Eur J Pharm Biopharm. 2004; 57(2):155-62.

https://doi.org/10.1016/j.ejpb.2003.10.015

6. Trevaskis NL, Charman WN, Porter CJ. Lipid-based delivery systems and intestinal lymphatic drug transport: a mechanistic update. Adv Drug Deliv Rev. 2008; 60(6):702-16. https://doi.org/10.1016/j.addr.2007.09.007

7. Clark MA, Jepson MA, Hirst BH. Exploiting M cells for drug and vaccine delivery. Adv Drug Deliv Rev. 2001; 50(1-2):81-106. https://doi.org/10.1016/S0169-409X(01)00149-1

8. Hussain N, Jaitley V, Florence AT. Recent advances in the understanding of uptake of microparticulates across the gastrointestinal lymphatics. Adv Drug Deliv Rev. 2001; 50(12):107-42. https://doi.org/10.1016/S0169-409X(01)00152-1

9. Murakami H, Kobayashi M, Takeuchi H, Kawashima Y. Preparation of poly(DL-lactide-co-glycolide) nanoparticles by modified spontaneous emulsification solvent diffusion method. Int J Pharm. 1999; 187(2):143-52. https://doi.org/10.1016/S03785173(99)00187-8

10. Mehnert W, Mäder K. Solid lipid nanoparticles: production, characterization and applications. Adv Drug Deliv Rev. 2001; 47(2-3):165-96. https://doi.org/10.1016/S0169409X(01)00105-3

11. Westesen K, Bunjas H, Koch MHJ. Physicochemical characterization of lipid 939 nanoparticles and evaluation of their drug loading capacity and sustained release potential. J Control Release 1997; 48:223-236.

https://doi.org/10.1016/S0168-3659(97)00046-1

12. Almeida AJ, Runge S, Muller R H. Peptide-loaded solid lipid nanoparticles (SLN): influence of production parameters. Int J
Pharm, 1997; 149:255-265. https://doi.org/10.1016/S03785173(97)04885-0

13. Rawat M, Singh D, Saraf S, Saraf S. Lipid carriers: a versatile delivery vehicle for proteins and peptides. Yakugaku Zasshi. 2008;128(2):269-80 https://doi.org/10.1248/yakushi.128.269

14. Yang SC, Lu LF, Cai Y, Zhu JB, Liang BW, Yang CZ. Body distribution in mice of intravenously injected camptothecin solid lipid nanoparticles and targeting effect on brain. J Control Release. 1999; 59(3):299-307. https://doi.org/10.1016/S01683659(99)00007-3

15. Smith A, Hunneyball IM. Evaluation of polylactid as a biodegradable drug delivery system for parenteral administration. Int J Pharm. 1986; 30:215-230. https://doi.org/10.1016/0378-5173(86)90081-5

16. Muller RH, MaaBen S, Weyhers H, Specht F, Lucks JS. Cytotoxicity of magnetite loaded polylactide, polylactide/glycolide particles and solid lipid nanoparticles (SLN) Int. J. Pharm. 1996; 138:8594. https://doi.org/10.1016/0378-5173(96)04539-5

17. Westesen K, Bunjes H. Do nanoparticles prepared from lipids solid at room temperature always possess a solid lipid matrix? Int. J. Pharm. 1995; 115:129-131. https://doi.org/10.1016/0378-5173(94)00347-8

18. Couvreur P, Dubernet C, Puisieux F. Controlled drug delivery with nanoparticles: current possibilities and future trends. Eur J Pharm Biopharm 1995; 41:2-13.

19. Almeida AJ, Souto E. Solid lipid nanoparticles as a drug delivery system for peptides and proteins. Adv Drug Deliv Rev. 2007 10; 59(6):478-90. https://doi.org/10.1016/j.addr.2007.04.007

20. Hu L, Tang X, Cui F. Solid lipid nanoparticles (SLNs) to improve oral bioavailability of poorly soluble drugs. J Pharm Pharmacol. 2004; 56(12):1527-35.

https://doi.org/10.1211/0022357044959

21. Lim SJ, Lee MK, Kim CK. Altered chemical and biological activities of all-trans retinoic acid incorporated in solid lipid nanoparticle powders. J Control Release. 2004 5; 100(1):53-61. https://doi.org/10.1016/j.jconrel.2004.07.032

22. Tabatt K, Kneuer C, Sameti M, Olbrich C, Müller RH, Lehr CM, Bakowsky U. Transfection with different colloidal systems: comparison of solid lipid nanoparticles and liposomes. J Control Release. 200418; 97(2):321-32.

https://doi.org/10.1016/j.jconrel.2004.02.029

23. Reithmeier H, Herrmann J, Göpferich A. Lipid microparticles as a parenteral controlled release device for peptides. J Control Release. 2001; 73(2-3):339-50. https://doi.org/10.1016/S0168-3659(01)00354-6

24. Jie, L; Tao, G; Changguang, W; Zhirong, Z; Zhirong, Z. Solid lipid nanoparticles loaded with insulin by sodium cholatephosphatidylcholine-based mixed micelles: preparation and characterization. Int J Pharm. 2007; 340:153-162. https://doi.org/10.1016/j.ijpharm.2007.03.009

25. Olbrich C, Gessner A, Schröder W, Kayser O, Müller RH. Lipiddrug conjugate nanoparticles of the hydrophilic drug diminazene-cytotoxicity testing and mouse serum adsorption. J Control Release. 2004 18; 96(3):425-35. https://doi.org/10.1016/j.jconrel.2004.02.024

26. Morel S, Ugazio E, Cavalli R, Gasco MR. Thymopentin in solid lipid nanoparticles. Int J Pharm. 1996; 132:259-261. https://doi.org/10.1016/0378-5173(95)04388-8

27. Avner DL. Clinical experience with pantoprazole in gastroesophageal reflux disease, Clin Ther. 2000; 22(10):11691185. https://doi.org/10.1016/S0149-2918(00)83061-1 
28. Cheer SM, Prakash A, Faulds D, Lamb HM Pantoprazole: an update of its pharmacological properties and therapeutic use in the management of acidrelated disorders, Drugs 2003; 63(1):101-133. https://doi.org/10.2165/00003495200363010-00006

29. Poole P. Pantoprazole. Am J Health Syst Pharm. 2001; 58(11):999-1008. https://doi.org/10.1093/ajhp/58.11.999

30. Ramachandraiah M, Rami Reddy YV. Method development and validation of HPLC for the determination and quantification of pantoprazole, Bull Environ Pharmacol Life Sci. 2012; 1(8):3942.

31. Thomas NR, Jack DR. Histamine and anti histaminic agents, in: Charles OW, Ole G, John HB, John MB (Eds.). Text Book of Organic Medicinal and Pharmaceutical Chemistry, eleventh ed., Lippincott Williams\& Wilkins, Pennsylvania, 2004; pp. 696-730.

32. Beil W, Staar U, Sewing KF. Pantoprazole: a novel Hp/K(p)ATPase inhibitor with an improved $\mathrm{pH}$ stability. Eur J Pharmacol. 1992; 218 (2-3):265-271. https://doi.org/10.1016/0014-2999(92)90178-7

33. Fitton A, Wiseman L. Pantoprazole. A review of its pharmacological properties and therapeutic use in acid-related disorders, Drugs 1996; 51(3):460-482. https://doi.org/10.2165/00003495-199651030-00012

34. Nishioka K, Nagao T, Urushidani T. Correlation between acid secretion and proton pump activity during inhibition by the proton pump inhibitors omeprazole and pantoprazole. Biochem Pharmacol. 1999; 58(8):1349-1359. https://doi.org/10.1016/S0006-2952(99)00211-7

35. Schubert MA, Müller-Goymann CC. Solvent injection as a new approach for manufacturing lipid nanoparticles-Evaluation of the method and process parameters. Eur J Pharm Biopharm. 2003; 55:125-31. https://doi.org/10.1016/S09396411(02)00130-3

36. Parmar B, Mandal S, Petkar K, Sawant K. Valsartan loaded solid lipid naoparticles: development, characterization, in-vitro and exvivo evaluation. Int J Pharm Sci Nanotechnol. 2011; 4:148390. https://doi.org/10.37285/ijpsn.2011.4.3.7

37. Peltonen L, Koistinen P, Karjalainen M, Hakkinen A, Hirvonen J. The effect of cosolvents on the formulation of nanoparticles from low molecular weight poly(l)lactide, AAPS Pharm Sci Tech, 2002; 3:1-7. https://doi.org/10.1208/pt030432

38. Cui F, Oian F, Yin C. Preparation and characterization of mucoadhesive polymercoated nanoparticles. Int J Pharm. 2006; 316:154-161. https://doi.org/10.1016/j.ijpharm.2006.02.031

39. Kreuter J. Evaluation of nanoparticles as drug delivery systems. I: Preparation methods. J. Pharm. Acta Helv. 1983; 58(7):196208.

40. Bourne DW. Pharmacokinetics In: Banker GS, Rhodes CT, eds. Modern Pharmaceutics. 4th ed, New York, NY: Marcel Dekker Inc, 2002:67-92.

41. Korsmeyer RW, Gurny R, Doelker E, Buri P, Peppas NA. Mechanisms of solute release from porous hydrophilic polymers. Int J Pharm.1983; 15:25-35. https://doi.org/10.1016/0378-5173(83)90064-9

42. Rinaki E, Valsami G, Macheras P. Quantitative biopharmaceutics classification system: the central role of dose/solubility ratio. Pharm Res. 2003; 20(12):1917-25. https://doi.org/10.1023/B:PHAM.0000008037.57884.11 